\title{
Spatial distribution of bovine cysticercosis-A retrospective study in Brazil from 2010 through 2015
}

\author{
Gabriel Augusto Marques Rossi ${ }^{\mathrm{a}, *}$, Isabella Vilhena Freire Martins ${ }^{\mathrm{b}}$, \\ Rafael Ferraço de Campos ${ }^{c}$, Luiz Filippe Simão Soares ${ }^{\mathrm{b}}$, \\ Henrique Meiroz de Souza Almeida ${ }^{a}$, Luis Antonio Mathias ${ }^{a}$ \\ a UNESP - Univ. Estadual Paulista, Faculdade de Ciências Agrárias e Veterinárias (FCAV), Departamento de Medicina Veterinária Preventiva e Reprodução \\ Animal, Via de acesso Paulo Castellane, s/n, CEP 14884-900 Jaboticabal, São Paulo, Brazil \\ ${ }^{\mathrm{b}}$ Universidade Federal do Espírito Santo, Alto Universitário s/n., Alegre, Espírito Santo, Brazil

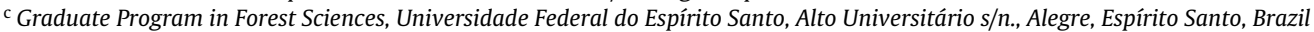

\section{A R T I C L E I N F O}

\section{Article history:}

Received 16 March 2017

Received in revised form 29 June 2017

Accepted 30 June 2017

\section{Keywords:}

Meat inspection

Geographical information system (GIS)

Parasites

Taenia saginata

Zoonoses

\begin{abstract}
A B S T R A C T
Geographical Information Systems (GIS) is frequently used in the control of animal diseases. In Brazil, the most impacting economical loss in the beef supply chain is bovine cysticercosis. This study focused on assessing the prevalence and geospatial distribution of bovine cysticercosis in 19 Brazilian states. To this, we gathered data from 146,346,244 bovines slaughtered between the years of 2010 and 2015 . The observed prevalence was $0.62 \%$ (C.I. $0.62-0.63$ ). In total, $30.86 \%$ cysticerci were viable, while $69.14 \%$ were unviable. Bovine cysticercosis cases had a significant decrease $(\mathrm{p}<0.05)$ during this period. The states of Paraná (2.01\%; C.I. 2.00-2.02), Santa Catarina (1.96\%; C.I. 1.93-2.00), São Paulo (1.77\%; C.I. 1.76-1.77), Rio Grande do Sul (1.63\%; C.I. 1.60-1.63) and Mato Grosso do Sul (0.80\%; C.I. 0.80-0.80) had the highest prevalence values. In some states a significant $(\mathrm{p}<0.05)$ decreasing trend was detected in the prevalence. In conclusion, Taenia-saginata-cysticercosis remains endemic in Brazil and interventions are necessary to maintain Brazilian beef competitive in the international food market and improve food safety to population.
\end{abstract}

(c) 2017 Elsevier B.V. All rights reserved.

\section{Introduction}

Taenia saginata is a parasite that infects humans and cattle during its adult and larval stages, respectively. The infection in cattle is asymptomatic even though, the condemnation of carcasses and viscera during meat inspection due to the presence of the parasite causes great losses to the beef production chain (WHO, 1983). The rejection of infected carcasses for human consumption is necessary since improperly cooked beef is the main infection source of taeniosis to humans (Bavia et al., 2012). Bovine cysticercosis is present worldwide and meat inspection is a strategic tool to assess the disease's prevalence and enhance prevention (Dutra et al., 2012).

According to Laranjo-González et al. (2016), epidemiological studies focused on producing accurate regional data and assessing epidemiological risks factors are critical to improve bovine cysticercosis control. In Brazil, few studies identified risk factors

\footnotetext{
* Corresponding author.

E-mail address: gabrielrossiveterinario@gmail.com (G.A.M. Rossi).
}

associated with bovine cysticercosis occurrence, such as cattle's access to uncontrolled water sources, presence of fishermen and proximity with areas of high human population density (Rossi et al., 2014, 2016). Furthermore, Geographical Information Systems (GIS) are useful in the adoption of sanitary programs focused on cysticercosis control (Dutra et al., 2012). Previous studies have been using GIS to study cysticercosis spatial distribution in several countries. In Brazil, Avelar et al. (2016), Guimarães-Peixoto et al. (2012), Rossi et al. (2016) and Pereira et al. (2017) mapped different regions based on the risk of cysticercosis occurrence in the states of Espírito Santo, Paraná, Mato Grosso and Mato Grosso do Sul.

This study aimed to assess the prevalence and geospatial distribution of bovine cysticercosis in 19 Brazilian states in order to provide useful information for sanitary programs development in Brazil.

\section{Materials and methods}

A data set of 146,346,244 bovines slaughtered from the years of 2010 through 2015 from farms located in 19 Brazilian states was 
Table 1

Number of animals slaughtered under SIF's supervision in 19 states of Brazil in the years of 2010 through 2015.

\begin{tabular}{|c|c|c|c|c|c|c|c|}
\hline States & 2010 & 2011 & 2012 & 2013 & 2014 & 2015 & Total \\
\hline Acre & 290,472 & 298,063 & 248,460 & 252,883 & 269,765 & 259,014 & $1,618,657$ \\
\hline Amazonas & 63,862 & 56,565 & 54,021 & 54,447 & 43,235 & 42,002 & 314,132 \\
\hline Bahia & 393,439 & 383,147 & 409,013 & 485,716 & 525,540 & 455,700 & $2,652,555$ \\
\hline Espírito Santo & 232,560 & 185,068 & 153,323 & 196,338 & 239,380 & 216,169 & $1,222,838$ \\
\hline Goiás & $2,292,659$ & $2,360,582$ & $2,547,814$ & $3,196,126$ & $3,319,009$ & $2,870,638$ & $16,586,828$ \\
\hline Maranhão & 370,216 & 375,162 & 351,303 & 350,650 & 445,606 & 480,781 & $2,373,718$ \\
\hline Minas Gerais & $1,669,824$ & $1,496,370$ & $1,815,042$ & $2,361,483$ & $2,522,585$ & $2,255,163$ & $12,120,467$ \\
\hline Mato Grosso do Sul & $3,133,036$ & $3,091,503$ & $3,762,931$ & $3,867,153$ & $4,027,430$ & $3,660,862$ & $21,542,915$ \\
\hline Mato Grosso & $3,818,791$ & $4,373,921$ & $5,058,333$ & $5,661,970$ & $5,219,459$ & $4,682,331$ & $28,814,805$ \\
\hline Pará & $1,604,600$ & $1,620,683$ & $1,641,112$ & $1,717,185$ & $1,860,665$ & $1,993,822$ & $10,438,067$ \\
\hline Paraná & $1,058,394$ & 887,138 & 960,100 & $1,033,525$ & $1,059,096$ & 916,017 & $5,914,270$ \\
\hline Rio de Janeiro & 10,432 & Missing data & Missing data & Missing data & Missing data & Missing data & 10,432 \\
\hline Rondônia & $1,908,092$ & $1,853,894$ & $2,050,000$ & $2,349,135$ & $2,174,772$ & $2,444,392$ & $12,780,285$ \\
\hline Roraima & 57,000 & 63,552 & 54,110 & 52,455 & 49,699 & 43,507 & 320,323 \\
\hline Rio Grande do Sul & 968,056 & 895,543 & 721,793 & 730,877 & 746,519 & 661,159 & $4,723,947$ \\
\hline Santa Catarina & 94,254 & 92,262 & 87,765 & 97,982 & 104,661 & 111,655 & 588,579 \\
\hline Sergipe & 45,774 & 41,703 & 41,858 & 45,966 & 45,891 & 37,699 & 258,891 \\
\hline São Paulo & $3,171,922$ & $2,916,692$ & $2,928,322$ & $3,148,038$ & $3,247,850$ & $2,762,796$ & $18,175,620$ \\
\hline Tocantins & 781,574 & 915,743 & 926,974 & $1,139,339$ & $1,092,203$ & $1,033,082$ & $5,888,915$ \\
\hline Total & $21,964,957$ & $21,907,591$ & $23,812,274$ & $26,741,268$ & $26,993,365$ & $24,926,789$ & $146,346,244$ \\
\hline
\end{tabular}

obtained from the Federal Inspection Service (SIF) of the Brazilian Ministry of Agriculture, Livestock and Food (MAPA). This information was obtained from the System of Information Management Information (SIGSIF) (http://www.agricultura.gov.br) of the SIF. The data contained the number of animals slaughtered daily, the number of animals infected with viable and unviable cysticerci and the state of origin. The states included in this study and the number of animals slaughtered per state are presented in Table 1.

The post mortem inspection of carcasses in Brazil is performed by agents properly trained to perform palpation and incisions in the carcasses, viscera, head (incisions in masseter and pterygoid muscles), tongue (palpation and incisions when necessary), heart (multiple incisions with atria and ventricles exposed), diaphragm and esophagus (Brazil, 1952).

The statistical analysis was performed using the software Epiinfo 3.5.1 (CDC, Atlanta, USA). The prevalence and the 95\% confidence interval (95\% C.I.) were calculated using the Wilson's Method (Thrusfield, 2010). Trend analyses were performed by Prais-Wisten estimation (Antunes and Valdman, 2002) using "Prais Package" in software R (R Core Team, 2016), v.3.3.2 (Mohr. 2015). For this purpose, data was transformed into natural logarithm. Prais-Winsten regression analysis was performed in order to obtain the regression coefficient (b1) and standard error. Annual percent change was established using formulae APC $=\left[-1+10^{\mathrm{b} 1}\right]^{*} 100$. Positive values where considered as "increasing temporal set" while negative ones were classified as "decreasing temporal set". "Stationary temporal set" category was used for those that did not differ from zero. 95\% C.I annual percent change was calculated using t distribution as multiplier - c. i. $95 \%=\left[-1+10^{\mathrm{b} 1-\left(\mathrm{t}^{*} \mathrm{SE}\right)}\right]^{*} 100 ;\left[-1+10^{\mathrm{b} 1+\left(\mathrm{t}^{*} \mathrm{SE}\right)}\right]^{*} 100$, where $\mathrm{t}=\mathrm{t}$ distribution value and $\mathrm{SE}=$ standard error

Maps of the states and of the spatial distribution of cysticercosis prevalence values included in this study were created in Terraview $^{\circledR}$ Software (INPE, São José dos Campos, Brazil, v.4.2.2) (www.dpi.inpe.br/terraview). The quantile method was used to create prevalence's map distribution.

\section{Results and discussion}

In total, 912,235 (0.62\%; C.I. 0.62-0.63) bovines were cysticerci infected out of 146,346,244 animals slaughtered between the years of 2010 and 2015 (Table 2). The viable cysticerci had a lower prevalence $(30.86 \%)$ than the not viable (69.14\%). The prevalence was higher when compared to European countries reports, such as in France (0.142\%) and Denmark (0.06\%) (Calvo-Artavia et al., 2013a;
Dupuy et al., 2014), highlighting the need of adopting prophylactic measures in cattle farms to improve food safety and increase the competitiveness of Brazilian beef chain in the international food market.

Thus, underestimations due to low sensitivity of the ongoing post-mortem inspection and diagnostic are likely to occur in several countries. According to Dupuy et al. (2012), the detection ratio of infected animals is around $11.5 \%$ (C.I. 7.4-17.1\%). Hypothetically, considering that the detection fraction is around $10 \%$ of infected animals, it would be possible to estimate that $9,122,350$ bovines were infected resulting in a real prevalence of $6.23 \%$.

In this study, the highest prevalence detected was during the year of 2010 (0.85\%; C.I. 0.84-0.85) and the lowest during 2015 (0.45\%; C.I. 0.45-0.46), agreeing with a significant reduction trend observed in Brazil during the period (Table 2). Thus, a significant reduction in prevalence was observed in the states of Goiás, Mato Grosso, Mato Grosso do Sul, Paraná, Pará, Roraima and São Paulo (Table 2). Dutra et al. (2012) evaluated bovine cysticercosis prevalence in Brazil between the years 2007 and 2010 and found 1.05\% prevalence value, higher than the value found in this study. The result highlights that important animal and human health improvements occurred in Brazil during this period.

The Brazilian law states that carcasses free or with single one cysticerci (that has to be removed) may be sold, except in the external market. On the other hand, carcasses with intense cysticercosis must be rendered. Finally, mild to moderate infections require freezing or canning (Brazil, 1952). Fukuda (2003) established that economical losses due to freezing treatment of infected carcasses were about US\$23.27 per infected animal in Brazil. Hypothetically, considering that, freezing treatment is done in about $30 \%$ of infected carcasses in Brazil (Rossi et al., 2014) and in this study, 912,235 carcasses were considered infected, we can estimate an economical loss of at least US\$ 8,308,821.00 only to Brazilian slaughterhouses.

The states of Paraná (2.01\%; C.I. 2.00-2.02), Santa Catarina (1.96\%; C.I. 1.93-2.00), São Paulo (1.77\%; C.I. 1.76-1.77) and Rio Grande do Sul (1.62\%; C.I. 1.60-.163) require interventions to control $T$. saginata-cysticercosis due to high prevalence values observed (Table 2 and Fig. 1). However, a possible bias in this study was the animal's movement to different farms and areas during their rearing steps. The states of São Paulo and Paraná have been pointed as responsible for raising Brazil overall cysticercosis prevalence (Dutra et al., 2012). The state of São Paulo has been pointed as "the one with highest prevalence" by Rossi et al. (2014). A high prevalence in the state of Paraná was previously reported 


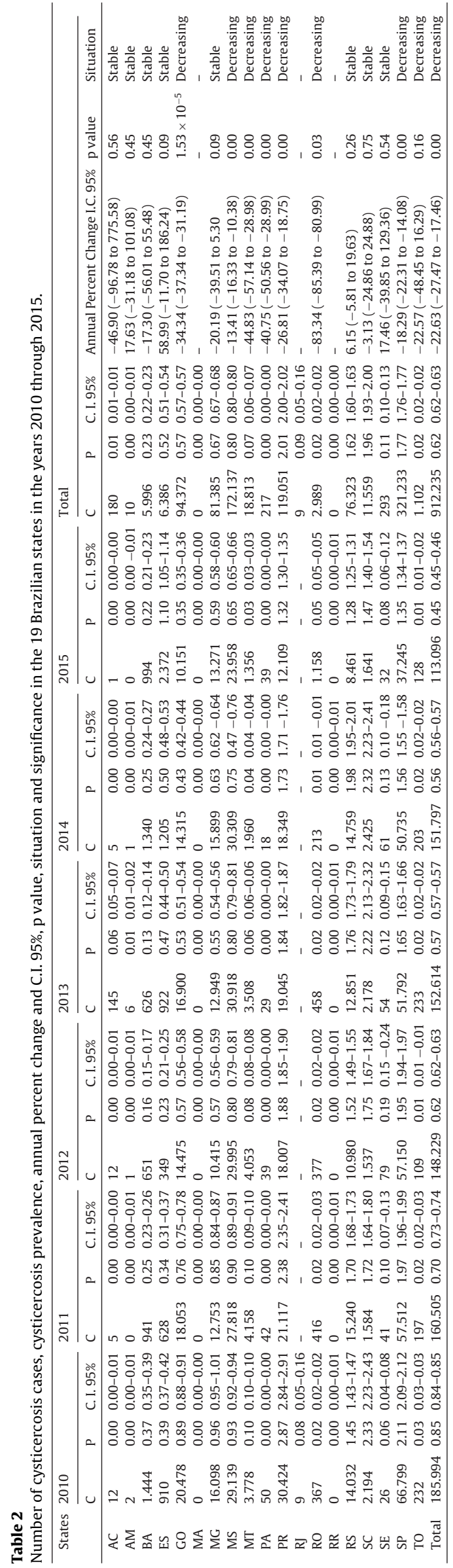

too (Guimarães-Peixoto et al., 2012). These authors established a bovine cysticercosis prevalence of $2.23 \%$ and significant economical losses due its occurrence from 2004 to 2008 highlighting that effective control measures were not adopted until this moment.

The Southern and Southeastern regions were the areas where the states showed highest prevalence (Fig. 1) These regions have higher social development, economic status and human population density. According to Rossi et al. (2016), high cysticercosis prevalence is directly associated with densely populated areas. The Brazilian states with the highest prevalence of bovine cysticercosis were Paraná (PR), Santa Catarina (SC), São Paulo (SP) and Rio Grande Sul (RS), all of them considered as densely populated (PR 52.4 inhab $/ \mathrm{km}^{2}, \mathrm{SC}-65.27$ inhab $/ \mathrm{km}^{2}, \mathrm{SP}-166.23$ inhab $/ \mathrm{km}^{2}$ and $\mathrm{RS}-37.96$ inhab $/ \mathrm{km}^{2}$ ) (IBGE, 2015).

In Brazil, meat inspection is performed according to the RIISPOA (Industrial and Sanitary Inspection of Animal Products Regulation (Brazil, 1952)) in order to prevent taeniosis in humans (Dutra et al., 2012) through the treatment or elimination of infected carcasses and by providing statistical data for epidemiological studies. In addition, models of carcass inspection based on risk-analysis of cattle origin, have been proposed to improve the efficacy of cysticerci detection (Calvo-Artavia et al., 2013b). A new risk-based meat inspection service performed by visual-only inspection of carcasses and viscera is being proposed in the European Union, highlighting the need of improvements in knowledge regarding bovine cysticercosis epidemiology and spatial distribution (Blagojevic et al., 2017).

GIS is useful for the development of control strategies. The distribution of bovine cysticercosis in several municipalities located in Brazilian states such as Paraná, Mato Grosso, Espírito Santo and Mato Grosso do Sul was already performed (Avelar et al., 2016; Guimarães-Peixoto et al., 2012; Rossi et al., 2016; Pereira et al., 2017). Thus, bovine cysticercosis occurrence in Brazil between the years of 2007 and 2010 was established (Dutra et al., 2012). Now, we present data regarding bovine cysticercosis occurrence from 2010 through 2015 in 19 Brazilian states. All these information regarding cattle infection origin should be used in new models of meat inspection in order to improve cysticercosis detection and $T$. saginata-cysticercosis control in the country. For instance, the ongoing model of beef inspection could be more effective through use of incisions in sites not considered as preferential but reported as with high parasitism level (Lopes et al., 2011) or use of serological exams as a screening method (Guimarães-Peixoto et al., 2016), but their cost-effectiveness are unknown.

Considering the broad distribution of $T$. saginata-cysticercosis in Brazil and its economical high-impact for beef production (Guimarães-Peixoto et al., 2012), high-occurrence areas should adopt prophylactic measures based on risk-analysis and monitoring interventions efficacies, as proposed by Braae et al. (2016). For instance, the adoption of Good Agricultural Practices (GAP) by cattle farms through supplying non-contaminated food and water to animals (Rossi et al., 2014).

Other several practices can be useful in cysticercosis control such as the preventing fecal contamination of water, proper treatment and destination of urban and rural sewages, promotion of health education, ending informal slaughter (WHO/FAO/OIE, 2002), improvements in farmers education and pharmacological treatment of animals (Laranjo-González et al., 2016). Furthermore, improving serological tests to detect infected animals before their slaughter still critical to control the disease and decrease the prevalence (Guimarães-Peixoto et al., 2016).

Our map regarding bovine cysticercosis prevalence can be useful to estimate the risk of taeniosis in human of bovine cysticercosis endemic areas, since both occurrences are related (Garro et al., 2015). The scientific community emphasizes the need of a 


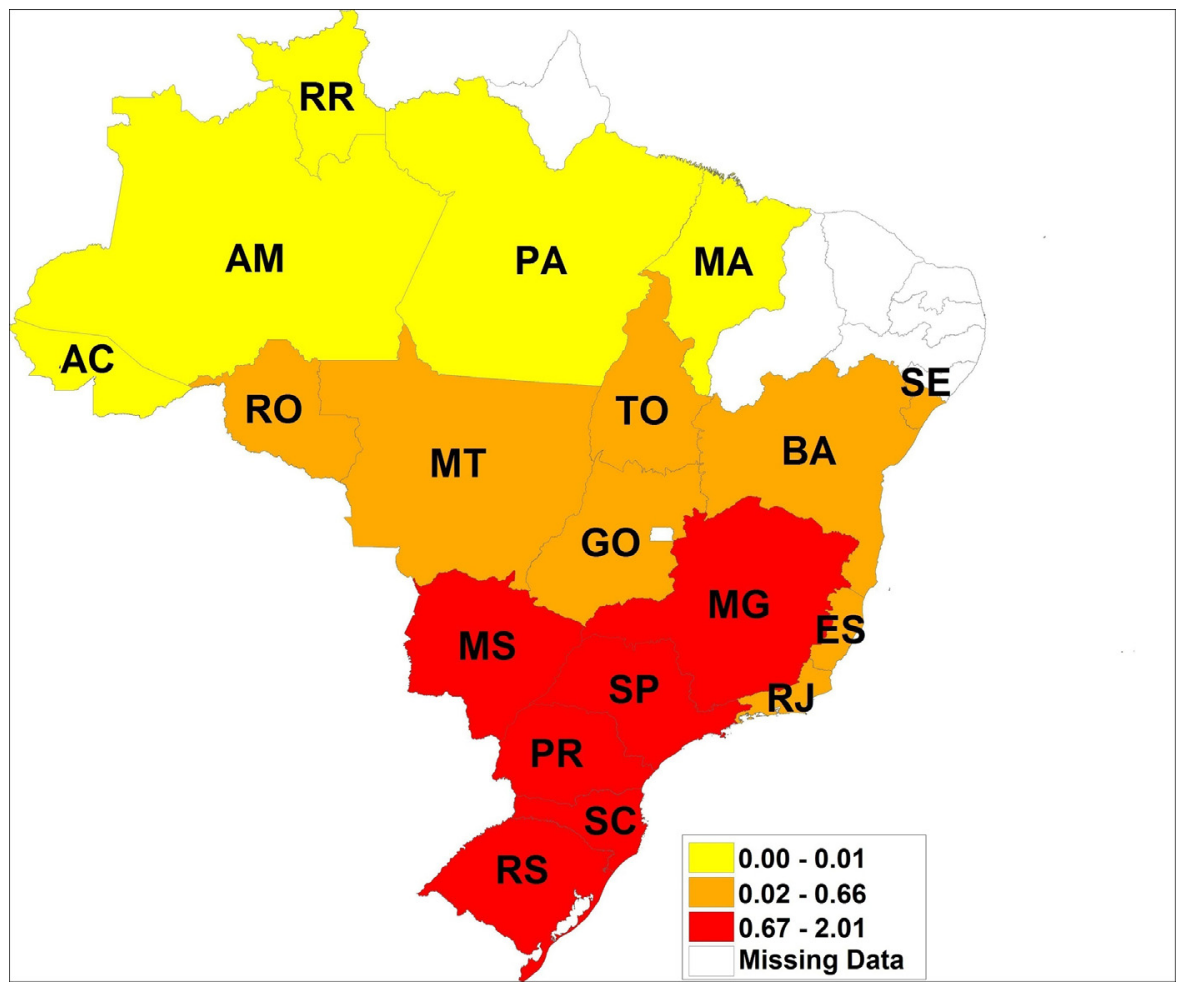

Fig. 1. Spatial distribution of the prevalence of bovine cysticercosis in 19 Brazilian states in the years of 2010 through 2015.

worldwide One Health Approach to achieve an effective control of taeniosis (Braae et al., 2017) and Brazil is not an exception.

\section{Conclusion}

Bovine cysticercosis remains endemic (0.62\%; C.I. 0.62-0.63) in Brazilian states and showed higher prevalence in those located in Southern and Southeastern Regions. Even though a decreasing trend in prevalence was detected, disease control still critical to reduce economical losses, enhance Brazilian beef competitiveness in the international food market and improve food safety. These results highlighted the importance of meat inspection and the creation of distribution maps to provide useful information for the development of new meat inspection models based on risk analyses.

\section{Acknowledgements}

We would like to thank the anonymous reviewers that collaborated to improve this manuscript quality.

\section{References}

Avelar, B.R., Marcelino, L.C., Campos, R.F., Santos, A.R., Martins, I.V.F., 2016. Spatia analysis on the risk of bovine cysticercosis occurrence in the state of Espírito Santo, Brazil. Parasit. Epidemiol. Control. 1, 116-123.

Blagojevic, B., Robertson, L.J., Vieira-Pinto, M., Johansen, M.V., Laranjo-González, M., Gabriel, S., 2017. Bovine cysticercosis in the European Union impact and current regulations, and an approach towards risk-based control. Food Control 78, 64-71, http://dx.doi.org/10.1016/j.foodcont.2017.02.052 (in press).

Braae, U.C., Devleesschauwer, B., Gabriel, S., Dorny, P., Speybroeck, N., Magnussen P., Torgerson, P., Johansen, M.V., 2016. Cysti-Sim- An agent-based model for Taenia solium transmission and control. PloS Negl. Trop. Dis. 10, e0005184.

Braae, U.C., Magnussen, P., Ndawi, B., Harrison, W., Lekule, F., Johansens, M.V., 2017. Effect of repeated mass drug administration with praziquantel and track and treat of taeniosis cases on the prevalence of taeniosis in Taenia solium endemic rural communities of Tanzania. Acta Trop. 165, 246-251.

Brazil Ministry of Agriculture, Livestock and Food Supply, 1952. Regulation of Industrial and Sanitary Inspection of Animal Products. Official Gazette, Brasilia, DF (29 May 1952).
Calvo-Artavia, F.F., Nielsen, L.R., Dahl, J., Clausen, D.M., Alban, L., 2013a. Occurrence and factors associated with bovine cysticercosis recorded in cattle at meat inspection in Denmark in 2004-2011. Prev. Vet. Med. 110, 177-182.

Calvo-Artavia, F.F., Nielsen, L.R., Alban, L., 2013b. Epidemiologic and economic evaluation of risk-based meat inspection for bovine cysticercosis in Danish cattle. Prev. Vet. Med. 108, 253-261.

Dupuy, C., Hendrikx, P., Hardstaff, J., Lindberg, A., 2012. Contribution of Meat Inspection to Animal Health Surveillance in Bovine Animals. EFSA Support. Publ. 9, 53, Available in: http://onlinelibrary.wiley.com/doi/10.2903/sp.efsa. 2012.EN-322/abstract, Accessed on: 02 February, 2017).

Dupuy, C., Morlot, C., Gilot-Fromont, E., Mas, M., Grandmontagne, C., Gilli-Dunoyer P., Gay, E., Callait-Cardinal, M.P., 2014. Prevalence of Taenia saginata cysticercosis in French cattle in 2010. Vet. Parasitol. 203, 65-72.

Dutra, L.H., Girotto, A., Vieira, R.F.C., Vierai, T.S.W.J., Zangirolamo, A.F., Marquês, F.A.C., Headley, S.A., Vidotto, O., 2012. The prevalence and spatial epidemiology of cysticercosis in slaughtered cattle from Brazil. Semin. Ciênc. Agrár. 33, 1887-1896.

Fukuda, R.T., Portuguese 2003. Contribuição ao estudo da epidemiologia da cisticercose bovina na região administrativa de Barretos. Aspectos ambientais e econômicos. 2003. 127p. Jaboticabal/SP. Tese (PhD Thesis). Universidade Estadual Paulista, Jaboticabal

Garro, F.L., Santos, T.M., Assis, D.C.S., Heneine, L.G.D., Ornellas, C.B.D., Pinto, P.S.A., Santos, W.L.M., 2015. Diagnosis of bovine taeniasis-cysticercosis complex in São João do Evangelista, Minas Gerais, Brazil. Pesq. Vet. Bras. 67, 1063-1069.

Guimarães-Peixoto, R.P.M., Souza, V.K., Pinto, P.S.A., Santos, T.O., 2012. Distribution and identification of risk areas for bovine cysticercosis in the state of Paraná, Brazil. Pesq. Vet. Bras. 32, 975-979.

Guimarães-Peixoto, R.P.M., Pinto, P.S.A., Santos, M.R., Polêto, M.D., Silva, L.F., Silva-júnior, A., 2016. Evaluation of a synthetic peptide from the Taenia saginata $18 \mathrm{kDa}$ surface/secreted oncospheral adhesion protein for serological diagnosis of bovine cysticercosis. Acta Trop. 164, 463-468.

IBGE. Brazilian Institue of Geography and StatisticS, 2015. States, Available in: <http://www.ibge.gov.br/estadosat/>Accessed on 02 February, 2017.

Lopes, W.D., Santos, T.R., Soares, V.E., Nunes, J.L., Mendonça, R.P., de Lima, R.C., Sakamoto, C.A., Costa, G.G., Thomaz-Soccol, V., Oliveira, G.P., Costa, A.J., 2011 Preferential infection sites of Cysticercus bovis in cattle experimentally infected with Taenia saginata eggs. Res. Vet. Sci. 90, 84-88.

Mohr, F., 2015. Prais-Winsten Estimation Procedure for AR(1) Serial Correlation, Available in: <https://cran.rproject.org/web/packages/prais/prais. pdf $>$ Accessed on 04 February, 2016.

Pereira, M.C., Rossi, G.A.M., Lopes, W.D.Z., Almeida, H.M.S., Mathias, L.A., Soares, V.E., 2017. Spatil analysis of bovine cysticercosis in the state of Mato Grosso do Sul, Brazil - the needs of interventions in animal and human populations. Vet. Parasitol. Reg. Stud. Rep. 8, 94-98.

R Core Team, 2016. R: A Language and Environment for Statistical Computing. R Foundation for Statistical Computing, Vienna, Austria. 
Rossi, G.A.M., Hoppe, E.G., Mathias, L.A., Martins, A.M.C.V., Mussi, L.A., Prata, L.F., 2014. Bovine cysticercosis in slaughtered cattle as an indicator of Good Agricultural Practices (GAP) and epidemiological risk factors. Prev. Vet. Med. $118,504-508$.

Rossi, G.A.M., Simoni, H.A.S., Lopes, W.D.Z., Almeida, H.M.S., Soares, V.E., Vidal, A.M.C., Ferraudo, A.S., Mathias, L.A., 2016. Prevalence and geospatial distribution of bovine cysticercosis in the state of Mato Grosso, Brazil. Prev. Vet. Med. 130, 94-98.
Thrusfield, M.V., 2010. Veterinary Epidemiology, 3 ed. Rocca, 556p.

WHO World Health Organization, 1983. Guidelines for Surveillance, Prevention and Control of Taeniasis/Cysticercosis. In: Gemmell, M., Matyas, Z., Pawlowski, Z., Soulsby, E.J.L. (Eds.), vph/8349th ed. World Health Organization, Geneva, p. 207

WHO, FAO, OIE, 2002. Guidelines for the Surveillance, Prevention and Control of Taeniosis/cysticercosis, Available in: <http://www.oie.int/doc/ged/d11245. pdf $>$ Accessed on 30 mar. 2016. 